\title{
O embate de diferentes campos discursivos
}

\section{The clash of different discursive fields}

\author{
Renato Sérgio de Lima \\ Chefe da Divisão de Estudos Socioeconômicos/Fundação Seade; \\ coordenador executivo do Fórum Brasileiro de Segurança Pública \\ renato@seade.gov.br
}

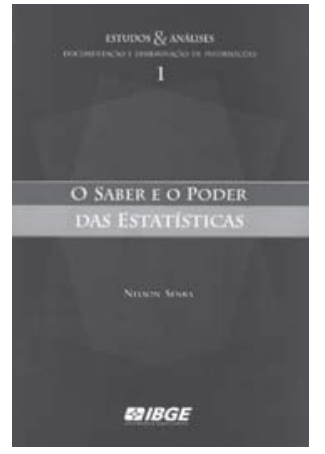

Senra, Nelson. O saber e o poder das estatísticas. Rio de Janeiro: IBGE,

2006. 332 p. (Estudos e Análises. Documentação e Disseminação de Informações, 1).

$\mathrm{L}$ ançado em 2005, O saber e o poder das estatísticas, de Nelson Senra, configura-se como referência fundamental da produção brasileira no campo da sociologia das estatísticas. Trata-se de esforço de síntese e exercício de erudição que merecem destaque e, mais, buscam consolidar um espaço de reflexão que muitas vezes pode ser tomado como secundário por certas posições do pensamento científico, mas que revela quão ainda é intensa a disputa discursiva em torno da objetividade e da verdade descritas a partir dos números. O livro não se esgota em si mesmo; e compõe parte de uma discussão que o autor tenta ampliar desde sua tese de doutorado, em 2000.

Nessa discussão, Senra demonstra que o conhecimento estatístico pode ser visto como resultante de inúmeros pressupostos históricos, científicos, políticos e ideológicos, que conformam, para além da técnica em si, a objetividade na aliança entre cumplicidade em torno de regras e normas oriundas de pactos e consensos e sua compreensão como valor moral. O ponto seria que, na concepção contemporânea da estatística, inaugurada no século XIX, seus procedimentos taxionômicos e sua associação com outras disciplinas ajudam a construir ou fixar verdades, e a circulação destas últimas vai depender de uma série de mecanismos de poder, em especial quando o foco está no rumo e sentidos do Estado.

Antes diluída em diferentes concepções sobre as formas de descrição das sociedades e dos Estados, a estatística ganha espaço como linguagem que organiza o saber científico em torno da quantificação: de ferramentas para a 'arte de governar' a instrumentos de medição da realidade, ela serviu ao propósito de quantificação de fatos sociais na tomada de decisão e na constituição de uma tecnologia de interpretação do social. De acordo com esse raciocínio, decisões baseadas em números seriam impessoais e estariam fundamentadas em pressupostos técnicos, constituindo, por conseguinte, uma resposta à demanda moral da imparcialidade do conhecimento. O século XIX, que coincidiu com o apogeu do positivismo, caracterizou-se, assim, por ser o momento histórico no qual as matrizes de desenvolvimento da estatística convergiram para a crença na objetividade e na quantificação da realidade, tão fundamentais à emergência da sociologia e das demais ciências humanas e sociais, por exemplo. 
O livro de Senra confirma que a análise sociológica das estatísticas exige serem as interpretações, os significados e segredos assumidos como elementos de compreensão da produção e utilização de dados estatísticos, uma vez que, ao deter a capacidade de 'coisificar' conceitos abstratos e fatos de realidade em números, as estatísticas são acionadas pelo debate político para validar discursos, tanto em favor da transparência quanto, em sentido contrário, em reforço do segredo. A identificação de suas regras de produção e utilização constitui, em consequência, um modo de análise sociológica das transformações sofridas ao longo da história política recente do país.

Em outras palavras, os registros estatísticos foram criados para delimitar e controlar fenômenos sociais e, com o avanço das técnicas disponíveis, ganham destaque também por intervir no estoque de conhecimentos sobre a realidade humana. A crença numa 'verdade' passível de guiar ações políticas e científicas exercia fascínio entre dirigentes estatais e cientistas no século XIX. Tal crença estava, também, fundada no estatuto ontológico dos números, que "se insinuam como linguagem universal, oferecendo-se para mediar diálogos". Entretanto, Senra observa que os números, em si, só são atribuíveis às coisas porque temos de identificar claramente os objetos observados e, portanto, as estatísticas não só tratam das coisas, mas também avocam a prerrogativa para coisificar as não-coisas. Ou seja, conceitos como crime, criminalidade, criminosos e violência, por exemplo, não são reduzíveis a objetos concretos no tempo e no espaço, mas traduzem situações e comportamentos sociais que sobressaem em meio a olhares e saberes.

O que a estatística faz, portanto, é acionar mecanismos de conversão de fatos observados em números e, como os números existem sem as coisas e podem ser aplicados a tudo, desenvolver métodos de manipulação e cálculo numérico. Ela vai ser o elemento de articulação de redes de informação que dependem da construção conceitual de objetos técnicos e científicos. No plano da linguagem, as estatísticas e suas regras matemáticas tencionam uma gramática dos números, e seu domínio implicará o domínio de regras de validação e circulação de interpretações acerca da realidade.

Alain Desrosières $(1992,1998,2001)$, outro nome de referência na sociologia das estatísticas, preocupado com a relação entre espaço público e estatísticas, toma o plano da linguagem como necessário para formalizar as coisas e destaca que ele não preexiste ao debate sobre a constituição de consenso e/ou elementos de referência comuns aos diferentes atores. Nessa mesma direção, Nelson Senra destaca que precisamos compreender quem oferece as estatísticas e como esse processo é realizado. Trata-se de discussão sobre o possível em contraponto ao desejável, que será conduzida na esfera de 'centros de cálculo'.

Para Bruno Latour $(2001,2004)$, tais centros se constituem em espaços encarregados de coordenar a transformação de um crescente volume de dados gerados pelos sistemas informatizados de informação em agregados estatísticos que sirvam ao governo do Estado e da sociedade. Na perspectiva de Latour, nos centros de cálculo são operados modelos de tradução dos registros individuais em sínteses complexas, em indicadores sobre variados fenômenos da realidade. Essa atividade, por sua vez, dependerá da qualificação e do conhecimento técnico dos diversos profissionais envolvidos. Por meio desses conhecimentos é que novos métodos, técnicas e desenhos de pesquisa quantitativa podem receber a chancela de qualidade, que torna seus resultados aceitáveis como 'objetivos e confiáveis'. A competência vai determinar o desempenho. 
Os centros de cálculo são, nas palavras de Haggerty (2001), um recurso de poder e ocupam lócus privilegiado para eventual articulação de tempos e conteúdos de oferta e demanda de informações estatísticas. De um lado, uma agenda de produção de dados que pode chegar ao limite da vigilância e do controle da população e do vigilante; do outro, a necessidade, governamental sobretudo, de dados que permitam o aumento de conhecimento sobre a realidade e, por conseguinte, a possibilidade de desenhos de políticas e ações de intervenção. Nesse lócus, a coordenação vai discutir as nomenclaturas e as técnicas utilizadas no levantamento dos registros estatísticos e determinar os discursos que melhor amparem as estratégias de dominação estabelecidas e que, por isso, serão disseminados.

As estatísticas estariam tensionadas pelo processo de distinção entre os tempos de oferta e a demanda de informações, ou seja, por um hiato entre aquilo que os planejadores de estatística desejam e imaginam como o ideal e o que os produtores dos registros administrativos que servem à compilação estatística fornecem e/ou divulgam. De um lado, os profissionais das agências/setores responsáveis por estatísticas tendem a ampliar o leque de situações monitoradas e a refinar, cada vez mais, técnicas de mensuração e controle. Por outro, os produtores e/ou executores das políticas monitoradas preocupam-se em produzir os dados necessários à operação do cotidiano de suas ações, relegando, como vimos, o debate sobre conteúdos dos dados a outras dimensões da lógica burocrática. Seriam duas posições antagônicas, que disputam um objeto por sua capacidade de ser contado ou, ao contrário, por suas individualidades intrínsecas, ou seja, disputas sobre o que contar e/ou quantificar. Em meio a essa disputa, as agências públicas de estatísticas ficam, muitas vezes, sem referenciais sobre a agenda de temas contemplados num sistema nacional ou regional de estatísticas.

Enfim, as discussões em torno de uma sociologia das estatísticas brasileiras têm, na obra de Nelson Senra, um importante ponto de apoio e de rigor . Se uma crítica pode ser tecida, todavia, ela caminha na direção do hermetismo que afeta os pesquisadores da área. Afinal, pouco avançamos na construção desse campo teórico e de seus métodos de investigação, e talvez tal fato ocorra em razão da inexistência de um projeto acadêmico e científico autônomo, que não se contente apenas com as fronteiras das disciplinas que mobilizam tais recursos de análise, mas também com o interior de seus objetos específicos e sem a preocupação com a conformação de um novo campo de estudos.

\section{REFERÊNCIAS}

DESROSIÈRES, Alain.

How real are statistics?: four possible attitudes. Social Research, New York, v.68, n.2, p.339-356. 2001.

DESROSIÈRES, Alain.

The politics of large numbers: a history of statistical reasoning. Cambridge: Harvard University Press. 1998.

DESROSIÈRES, Alain.

Discuter l'indiscutable: raison statistique et espace public. In: Cottereau, Alain ; Ladriere,
Paul (Ed.). Raison pratiques, 3. Pouvoir et légitimité. Paris : Editions de EHESC. p.131-154. 1992.

LATOUR, Bruno.

Scientific objects and legal objectivity.

Disponível em: http://www.bruno-latour.fr/ articles/article/088.html. 2004.

LATOUR, Bruno.

A esperança de Pandora. Bauru: Edusc. 2001.

HAGGERTY, Kevin D.

Making crime count. Toronto: University Of Toronto Press. 2001. 